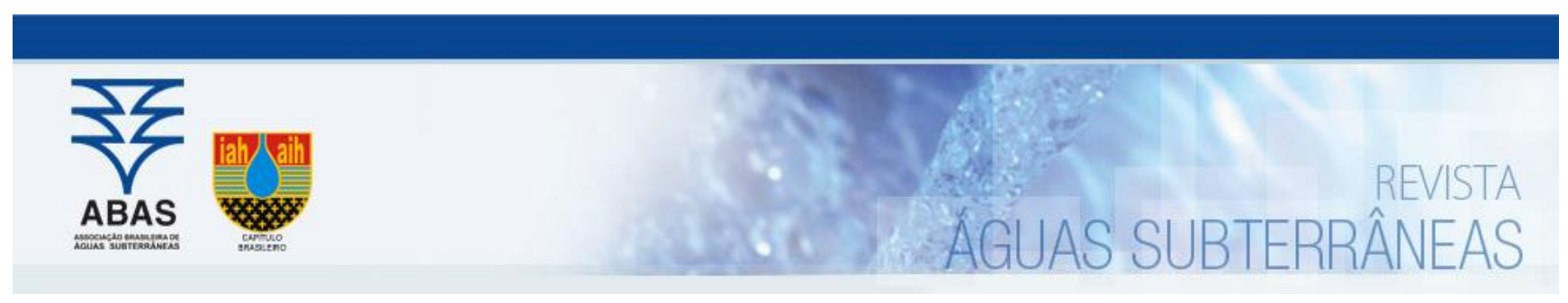

Artigos

\title{
Gestão integrada dos recursos hídricos: avaliação dos benefícios do uso conjunto de águas superficiais e subterrâneas em uma região no sul do Brasil
}

\section{Integrated water resources management: assessment of the benefits from conjunctive use of surface water and groundwater in southern Brazil}

\author{
Camila Dalla Porta Mattiuzi1; Guilherme Fernandes Marques $^{2} \bowtie$ \\ ${ }^{1}$ Companhia de Pesquisa de Recursos Minerais (CPRM/SGB), Porto Alegre, RS \\ 2 Instituto de Pesquisas Hidráulicas/Universidade Federal do Rio Grande do Sul (IPH/UFRGS), Porto Alegre, RS \\ camila.mattiuzi@cprm.gov.br, guilherme.marques@ufrgs.br
}

\author{
Palavras-chave: \\ Gestão de recursos hídricos. \\ Uso conjunto. \\ Gestão integrada. \\ Modelo hidroeconômico.
}

\section{Keywords:}

Water resources management. Conjunctive use.

Integrated management.

Hydroeconomic model.

Revisado por pares.

Recebido em: 02/05/2019.

Aprovado em: 19/08/2019.

\section{Resumo}

O uso de água subterrânea vem crescendo como alternativa para o atendimento das demandas hídricas, porém muitas vezes sem o manejo adequado. Este trabalho apresenta o conceito do uso conjunto dos recursos hídricos superficiais e subterrâneos enquanto ferramenta para criar o elo de conexão entre o conhecimento sobre o meio físico e as decisões no âmbito da gestão da água. São identificadas possíveis estratégias de uso conjunto para uma região no sul do Brasil a partir do cálculo do potencial de benefícios econômicos com uso de ferramenta matemática de simulação e otimização hidroeconômica. Os resultados apontam redução da escassez hídrica e aumento no atendimento das demandas com o uso do manancial subterrâneo, sendo também analisada a integração das estratégias frente à legislação brasileira de recursos hídricos.

\begin{abstract}
Groundwater use has been increasing as an alternative to meet water demands, but often without proper management. This paper presents the concept of conjunctive use of surface and groundwater resources as a tool to create the link between knowledge about the physical environment and water management decisions. Conjunctive use strategies for a region in southern Brazil are identified from the potential economic benefits calculation with the use of mathematical simulation tool of hydroeconomic optimization. The results show a reduction in water scarcity and increase in meeting the demands with groundwater use, and also the integration of the strategies with the Brazilian legislation of water resources.
\end{abstract}

DOI: http:/dx.doi.org/10.14295/ras.v33i4.29542

\section{INTRODUÇÃO}

Os sistemas hídricos superficiais e subterrâneos vêm se mostrando sobrecarregados em diversas regiões no mundo, principalmente devido ao aumento da demanda por água, ocasionado pelo crescimento populacional e econômico (ROSS, 2017, TABARI; YADZI, 2014). Conforme relatório da Organização das Nações Unidas (ONU, 2015) existe uma projeção de que a demanda hídrica mundial deva aumentar mais de $40 \%$ até 2050. No Brasil, mesmo com uma elevada oferta de água, a má distribuição geográfica deste recurso e a falta de uma gestão eficaz têm contribuído para graves crises de escassez hídricas em algumas regiões do país (ANA, 2010; 2013), tornando cada vez mais urgente o planejamento integrado e a efetividade da gestão dos recursos hídricos (FASAKHODI;
NOURI; AMINI, 2010).

Nas últimas décadas, a utilização de água subterrânea aumentou de maneira rápida e intensa, porém sem o acompanhamento técnico adequado (HERRÁlZ, 2009); estima-se que aproximadamente $20 \%$ dos aquíferos mundiais estejam atualmente superexplotados (GLEESON et al, 2012). Historicamente tem sido abordada separadamente a gestão das águas superficiais e subterrâneas, ignorando a relação existente e a interdependência entre ambos mananciais. No Brasil, a aplicação de instrumentos de gestão desconsidera essa interdependência, contribuindo para a ocorrência de conflitos e a interferência do uso de um manancial na disponibilidade do outro (SOARES e VELASQUEZ, 2013). No meio técnico é de amplo conhecimento que o comportamento destes mananciais não 
se dá de forma isolada, de maneira que o uso ou a contribuição de um recurso tem, normalmente, efeito sobre o outro. Essa natureza distinta e complementar é fundamental para a gestão dos recursos hídricos, devendo tais diferenças serem exploradas para o benefício econômico, proteção ambiental e, sobretudo, segurança (robusteza) dos sistemas hídricos (SAHUQUILLO, 2009). Entretanto, verifica-se aqui uma lacuna de conhecimento: como trazer para os instrumentos de gestão e para as políticas públicas a informação necessária para decisões mais efetivas? Além do conhecimento sobre o comportamento hidrológico e hidrogeológico, devem ser explorados os aspectos operacionais e econômicos presentes no manejo integrado dos sistemas superficiais e subterrâneos, de modo a estabelecer um elo de conexão entre o conhecimento sobre o meio físico e as decisões no âmbito da gestão da água.

O uso conjunto consiste em uma estratégia de gerenciamento na qual são utilizados, de forma coordenada e integrada, os recursos disponiveis de água superficial e subterrânea, de maneira a explorar as propriedades de ambos mananciais (PULIDO-VELAZQUES et al., 2003, ROSS, 2017) e produzir mais benefícios do que se os mananciais fossem operados de forma independente e isolada (SINGH, 2014, ROSS, 2017). Recentemente, o manejo conjunto dos recursos hídricos foi apresentado como um princípio chave pelo projeto de Governança Global da Água Subterrânea (GGGFA, 2015). Em alguns países o conceito de uso conjunto já encontra diversas aplicações, como atendimento às demandas urbanas (DAl et al, 2016; DRAPER et al, 2003), atendimento aos níveis de potabilidade exigidos (FILIMONOVA \& BALDENKOV, 2015), diminuição da escassez hídrica (ABDOLVANDI et al, 2014), atendimento às demandas agrícolas e industriais (RAUL \& PANDA, 2013; REZAEI, SAFAVI \& ZEKRI, 2017), maximização de benefícios econômicos (SINGH, 2016), recuperação de aquíferos deplecionados (KAHIL et al, 2016; MANI et al, 2016) e de ecossistemas (WU et al, 2015).

O presente artigo explora o conceito de uso conjunto como ferramenta para o gerenciamento efetivo dos recursos hídricos. Esse artigo contribui para a área de conhecimento através da identificação de possíveis estratégias de uso conjunto para uma região de estudo (Bacia do Rio Santa Maria/RS) a partir do cálculo do potencial de benefícios econômicos com emprego de ferramenta matemática de simulação e otimização hidroeconômica, e também da análise da integração dessas estratégias frente à legislação brasileira de recursos hídricos, apontando direções para planos e ações.

\section{ESTUDO}

Localizada na região sul do Brasil, a Bacia Hidrográfica do Rio Santa Maria (BHSM) apresenta recorrentes episódios de escassez, pois o período de baixa disponibilidade hídrica coincide com o início da irrigação das áreas cultivadas com arroz e soja (ANA, 2006). Na BHSM existem em torno de 239 mil ha de área plantada, sendo 65\% soja e 35\% arroz; a demanda total de água para essas culturas irrigadas foi estimada em $1.776 \mathrm{hm}^{3}$ por ano; os mananciais utilizados para irrigação são principalmente superficiais (reservatórios e rios). Os produtores da BHSM possuem uma cultura de armazenamento de água devido à concentração da precipitação nos meses de inverno, enquanto que a demanda para irrigação ocorre nos meses se setembro a fevereiro; conforme o Plano de Recursos Hídricos da BHSM existem 2.157 açudes, totalizando um volume armazenado de 1.104 hm $^{3}$ (DRH/SEMA, 2016); estes reservatórios são abastecidos principalmente pela captação do escoamento superficial, bem como por bombeamento direto dos cursos d'água.

A Geologia da BHSM é composta por rochas sedimentares que apresentam características de formação aquífera (como os arenitos e depósitos aluviais), até rochas basálticas (como a Formação Serra Geral, que pode apresentar boa capacidade aquífera) e rochas cristalinas (Embasamento Cristalino que, nesta região, constitui um aquífero de baixo potencial); regiões compostas predominantemente de rochas pertencentes ao Sistema Aquífero Guarani são importantes com relação à recarga, pois os processos de infiltração vertical e efetiva são facilitados devido à grande permeabilidade dos estratos de superfície (CPRM, 2007). A existência de disponibilidade subterrânea na BHSM configura um cenário que possibilita a aplicação de estratégias de uso conjunto.

Para as simulações a BHSM foi dividida em seis regiões que compreendem os municípios da bacia; no entanto, os municípios não estão totalmente inseridos nos limites da bacia, sendo feitas ponderações pela área do município que faz parte da BHSM. Na Figura 1 está apresentada a localização da área de estudo e as regiões; também estão apresentadas as estações hidrológicas (ANA, 2016), a geologia (CPRM, 2007), as áreas plantadas de arroz e soja (IBGE, 2015), e a precipitação média na Bacia (CPRM, 2019). 
Figura 1 - Localização e caracterização da BHSM

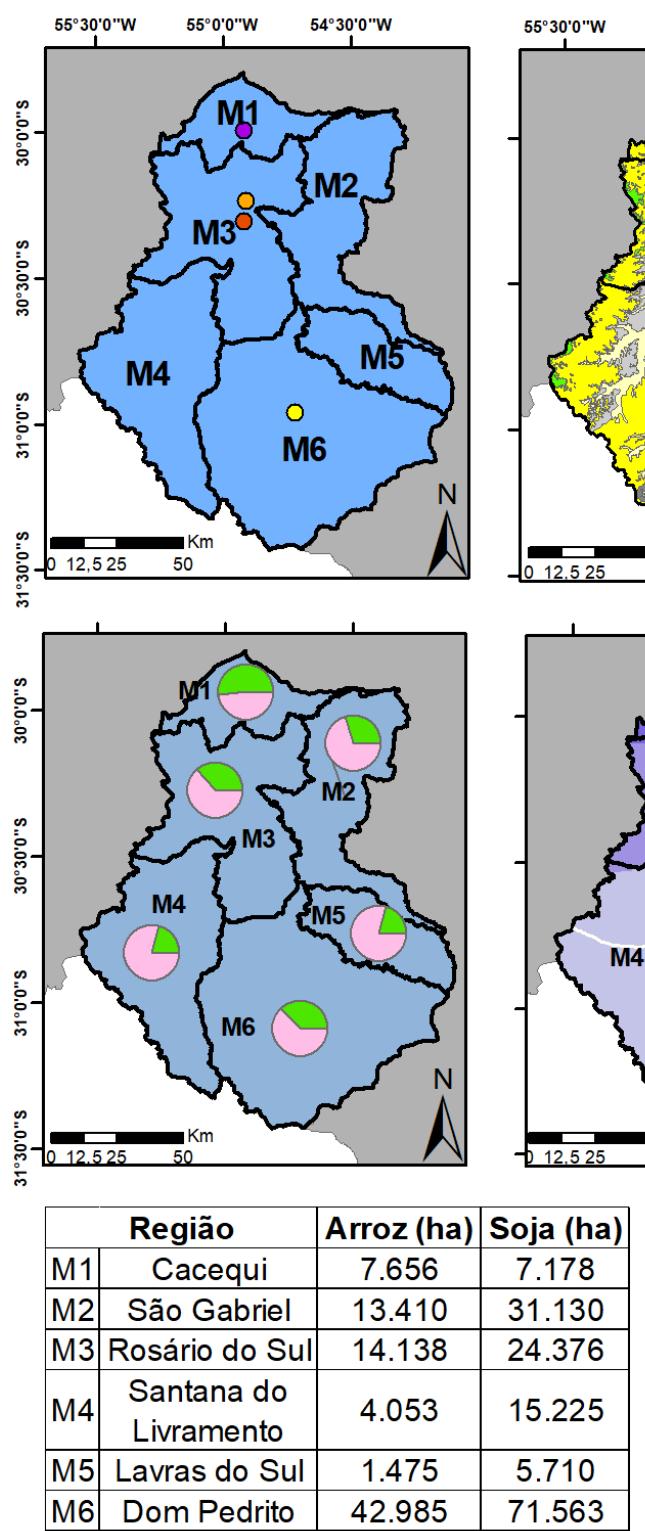

\section{MATERIAIS E MÉTODOS}

Nesta seção são apresentados os métodos utilizados para o estudo do potencial de benefícios econômicos a partir do uso conjunto de água superficial e subterrânea na Bacia do Rio Santa Maria. Na seção 3.1 é apresentada a obtenção da disponibilidade hídrica superficial, a qual foi realizada através do uso do Modelo Hidrológico de Grandes Bacias MGB-IPH (COLLISCHONN et al., 2007) para obtenção das séries temporais de vazões superficiais, e a classificação de imagem de satélite para obtenção da espacialização de reservatórios de água na área da bacia hidrográfica; na seção 3.2 é apresentada a obtenção da reserva subterrânea explotável através do Filtro de Eckhardt de separação de escoamento de base (ECKHARDT, 2005); na seção 3.3 é apresentado o modelo matemático de simulação e otimização hidroeconômica, o qual avalia a alocação otimizada para reduzir o custo da escassez.

\subsection{Recursos hídricos superficiais}

Para utilização do modelo hidroeconômico é necessário como

\section{Legenda \\ $\square$ Regiões
Bacia Santa Maria}

\section{Estações Hidrológicas}

- Cacequi

- Ponte lbicuí da Armada

- Rosário do Sul

- Dom Pedrito

\section{Áreas plantadas}

$\square$ Arroz

Soja

\section{Geologia}

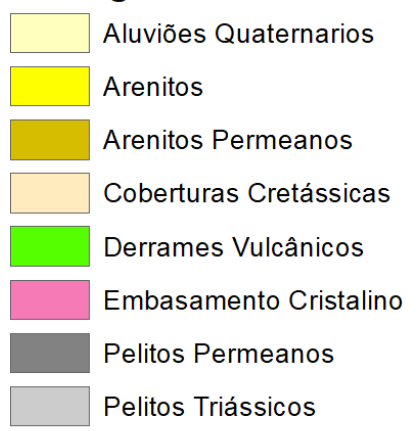

Precipitação Média (mm/ano)
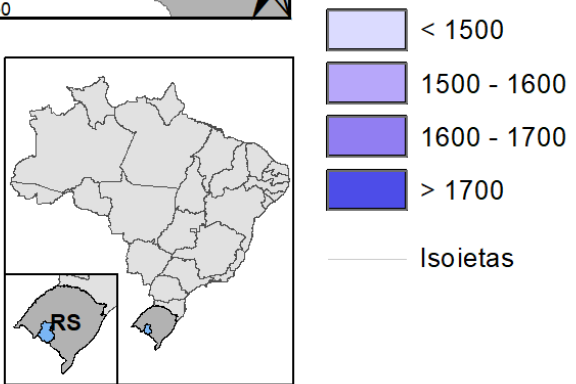

dado de entrada a disponibilidade hídrica superficial, ou seja, as vazões dos rios e os volumes armazenados em reservatórios na BHSM.

As séries temporais de vazões superficiais foram obtidas a partir do modelo MGB-IPH (COLLISCHONN et al., 2007), que é um modelo chuva-vazão semi-distribuído no qual a bacia hidrográfica é discretizada em pequenas áreas de drenagem e em cada uma é calculado o balanço vertical de água no solo; estes volumes são liberados na rede de drenagem e a vazão é propagada utilizando o método linear Muskingum-Cunge. 0 modelo foi executado para os anos de 2000 a 2015, gerando 16 anos de séries de vazões. Os dados de entrada para o MGB-IPH foram o modelo digital de elevação SRTM 90m (FARR et al., 2007), classes de respostas hidrológicas (FAN et al., 2015), e dados de vazão e precipitação (ANA, 2016), que foram utilizadas para a calibração. 0 modelo foi calibrado para quatro estações hidrológicas pluviométricas e fluviométricas: Dom Pedrito (76251000), Rosário do Sul (76310000), Ponte Ibicuí da Armada (76300000), e Cacequi (76370000); a calibração do modelo resultou em um coeficiente médio de Nash- 
Sutcliffe superior a 0,75. Mais informações sobre a utilização do modelo hidrológico MGB-IPH estão disponíveis em Mattiuzi (2018).

Os volumes armazenados nos reservatórios particulares foram obtidos através da classificação por NDWI de uma imagem de satélite (Landsat de Outubro de 2015); foi escolhida a imagem deste mês pois ele antecede o início do período de irrigação na BHSM e os reservatórios devem estar nos seus maiores níveis. A partir da classificação da imagem de satélite foi obtida a distribuição e a área superficial dos reservatórios; para estimar o volume de água disponível foi utilizada a equação volume $x$ área superficial disponivel em DRH/SEMA (2016).

\subsection{Recursos hídricos subterrâneos}

Para avaliar a possibilidade de implementação de estratégias de uso conjunto é necessário quantificar a reserva subterrânea que pode ser utilizada.

Conforme ANA (2010) as reservas subterrâneas podem ser divididas entre permanente e ativa; a reserva ativa corresponde ao volume armazenado entre os níveis de flutuação máximo e mínimo do nível d'água subterrâneo. A reserva ativa é obtida com o escoamento de base menos a vazão mínima superficial. A reserva explotável é o volume disponível para uso de água subterrânea que permite a sustentabilidade do recurso, sendo definida como $50 \%$ da reserva ativa.

Para a obtenção da reserva ativa é necessário o escoamento de base; neste trabalho foi utilizado o filtro de separação de escoamento de base de Eckhardt (2005) aplicado nas séries históricas de vazão dos postos fluviométricos Rosário do Sul e Dom Pedrito. 0 filtro de Eckhard é um algoritmo que realiza a separação da vazão de um curso d'água em duas componentes: escoamento superficial e escoamento de base. Maiores informações sobre o método de separação dos escoamentos de base do Filtro de Eckhardt e a sua utilização na Bacia Hidrográfica do Rio Santa Maria está disponível em Mattiuzi et al. (2015) e Mattiuzi (2018).

É importante ressaltar que neste estudo a reserva subterrânea foi estimada utilizando a BHSM como unidade territorial, entretanto sabemos que as unidades aquíferas não estão dispostas de maneira uniforme ao longo de toda a área da bacia, conforme apresentado na descrição da área de estudo anteriormente. 0 detalhamento sobre a utilização de água subterrânea no modelo hidroeconômico é apresentado na seção seguinte.

\subsection{Modelo hidroeconômico}

No modelo de otimização hidroeconômico, o qual é representado matematicamente por uma rede de arcos e nós, sujeito a restrições físicas, legais e institucionais, a função objetivo é minimizar o custo da escassez. É importante definir a diferença entre seca e escassez hídrica: seca é a falta de disponibilidade de recurso hídrico, enquanto escassez hídrica é a diferença entre a quantidade de água utilizada pelo usuário e quantidade que o mesmo usaria se a disponibilidade fosse irrestrita e sem custo (JENKINS et al., 2004). A escassez hídrica tem um custo, que é definido pelo benefício econômico que o usuário deixa de ter por não ter o acesso à quantidade de água que gostaria (DRAPER et al., 2003).

O modelo hidroeconômico faz alocação da água entre as regiões para atender às demandas existentes segundo o seu custo da escassez, buscando minimizar o custo total da escassez em toda a bacia. As demandas hídricas são representadas por regiões homogêneas, as quais possuem uma função de penalidade econômica convexa representada por uma aproximação piecewise linear de múltiplos segmentos o que permite o emprego de um algoritmo de otimização linear de resolução rápida. O custo da escassez é calculado pelas funções de valor marginal da água, que variam conforme o mês e as características de cada região (principais culturas plantadas, produtividade, custos e benefícios). As funções de valor marginal da água foram obtidas com o emprego de um modelo de otimização de produção agrícola elaborado e calibrado para a BHSM em Mattiuzi (2018), o qual emprega abordagem de programação matemática positiva baseado em Howitt et al. (2012).

O custo da escassez (CTE) para uma dada região calculado pela Equação 1, onde CMAX é o custo de escassez máximo para cada intervalo de tempo $t, \mathbf{X}$ é a fração de água alocada para a região para cada intervalo de tempo e $\mathbf{C M}$ é a declividade de cada segmento linear da função de penalidade convexa, para cada região e cada intervalo de tempo.

$$
C T E=\sum_{t}\left(C M A X+\sum X * C M\right)
$$

Se, em um mês, uma região tem disponível uma quantidade de água igual à sua demanda máxima, o custo da escassez é zero, pois a demanda pode ser atendida plenamente. Se a disponibilidade hídrica é inferior à demanda máxima, existe escassez, e por consequência, custo da escassez. Se a disponibilidade hídrica é igual à $50 \%$ da demanda máxima, o custo da escassez é máximo, pois neste estudo disponibilidades hídricas inferiores a $50 \%$ da demanda máxima encontram-se fora do domínio das funções de valor marginal da água.

O modelo foi simulado no sistema GAMS (General Algebraic Modeling System - BROOKE et al., 1998), com passo mensal, para um período de 16 anos (2000 a 2015); foram consideradas as áreas plantadas e demandas hídricas referentes ao ano de 2015; também foi considera que as demandas não mudaram durante o período analisado. 0 detalhamento sobre o modelo pode ser encontrado em Mattiuzi (2018) e Mattiuzi et al. (2019) e não foram incluídos nesse artigo por limitação de tamanho.

No modelo hidroeconômico foi simulado um cenário base (CB) que representa as condições atuais da BHSM (disponibilidade superficial de rios e reservatórios particulares para o atendimento das demandas), e um cenário que, além da disponibilidade superficial, possui disponibilidade de água subterrânea $(\mathrm{CB}+\mathrm{GW})$. Nas simulações $\mathrm{CB}+\mathrm{GW}$ a disponibilidade subterrânea foi simulada como um reservatório no qual está disponível, anualmente, a reserva explotável calculada anteriormente. A utilização da reserva explotável pelo modelo para atender as demandas corresponde ao ciclo anual do escoamento de base; esta restrição foi colocada para prevenir que o modelo retirasse grandes quantidades de água subterrânea 
em curtos períodos de tempo e assim deplecionasse o aquífero.

É importante ressaltar que no modelo não houve distinção entre as unidades aquíferas, sendo considerado que a reserva subterrânea explotável estava disponível para atender as demandas em todas as regiões analisadas; além disso, não foram avaliados os custos de bombeamento e distribuição de água subterrânea para as demandas, pois o objetivo desse estudo não é avaliar a viabilização do uso de água subterrânea na BHSM, mas avaliar o impacto econômico no custo da escassez hídrica mediante a disponibilidade de água subterrânea para o atendimento das demandas.

\section{RESULTADOS E DISCUSSÕES}

Nesta seção são apresentados os resultados das simulações do modelo hidroeconômico. Na seção 4.1 é avaliado o atendimento às demandas nos cenários $C B$ e $C B+G W$; na seção 4.2 é avaliado o uso de água subterrânea; na seção 4.3 é avaliado o impacto do uso de água subterrânea na redução do custo da escassez; na seção 4.4 são apresentadas estratégias de uso conjunto que podem ser implementadas na BHSM, e na seção 4.5 é discutida a integração dos resultados frente à legislação brasileira de recursos hídricos.

O modelo hidroeconômico foi executado para 16 anos, porém o primeiro ano foi excluído da apresentação dos resultados devido ao ajuste inicial do modelo; portanto, todos os resultados aqui apresentados são referentes a 15 anos de simulação (2001 a 2015). Através do filtro digital de Eckhardt foi estimada a reserva subterrânea explotável em $716 \mathrm{hm}^{3} /$ ano na BHSM.

\subsection{Atendimento às demandas}

A Figura 2 mostra o volume acumulado $\left(\mathrm{em} \mathrm{hm}^{3}\right)$ em cada região, para os 15 anos de simulação do modelo: demanda agrí cola (vermelho), o volume da Alocação CB (azul), e o volume da Alocação CB+GW (verde).

Analisando o caso base percebe-se que nas regiões M1, M2,
M5 e M6 é verificada escassez hídrica, em razão da elevada demanda agrícola e reduzida disponibilidade superficial. Já no caso $\mathrm{CB}+\mathrm{GW}$ percebe-se que o emprego da água subterrânea permitiu aumento no volume de água alocado para o atendimento das demandas agrícolas, reduzindo a escassez nas regiões M1, M2, M5 e M6, indicando um potencial benefício do uso de água subterrânea para complementar a demanda de irrigação na BHSM. Mesmo existindo uma variação ao longo dos anos na alocação CB das regiões M1, M2, M5 e M6, em nenhum ano houve atendimento à demanda; já com a alocação $C B+G W$ houve aumento na disponibilidade hídrica, e em algumas regiões atendimento total à demanda. Nas regiões M3 e M4 a demanda foi atingida com a alocação CB, indicando que não existe necessidade do aumento da disponibilidade hídrica.

\subsection{Uso de água subterrânea}

A Figura 3 apresenta o volume anual de água subterrânea utilizado ao longo dos 15 anos de simulação em todas as regiões. Percebe-se que nas regiões M6, M2 e M1 ocorreu o uso dos maiores volumes de água subterrânea, em média $478 \mathrm{hm}^{3} / \mathrm{ano}, 162 \mathrm{hm}^{3} /$ ano e $60 \mathrm{hm}^{3} /$ ano, respectivamente; este resultado é devido às áreas plantadas e também à relação entre os cultivos de arroz e soja (pois as demandas por água de cada cultura variam).

O volume de água subterrânea utilizado na BHSM foi inferior a reserva explotável calculada em todos os anos simulados, com exceção do ano de 2006, o qual foi um ano de estiagem; neste ano o volume alocado pelo modelo foi de $1.915 \mathrm{hm}^{3}$, ou seja, 2,6 vezes maior que a reserva explotável. Deve-se destacar que o valor da reserva explotável foi obtido a partir da recarga média estimada pela separação de escoamento de base e, no modelo hidroeconômico, a reserva foi mantida constante com disponibilidade anual; entretanto, sabe-se que a reserva ativa de um aquífero é variável. Portanto, para a avaliação da implementação de estratégias de uso conjunto devese estudar as variações na disponibilidade subterrânea ao longo do tempo. 
Figura 2 - Volume acumulado (em $\mathrm{hm}^{3}$ ) para os 15 anos de simulação do modelo, para cada ano e região: demanda agrícola (vermelho), Alocação Caso Base (azul), e Alocação CB+GW (com disponibilidade de água subterrânea - verde)
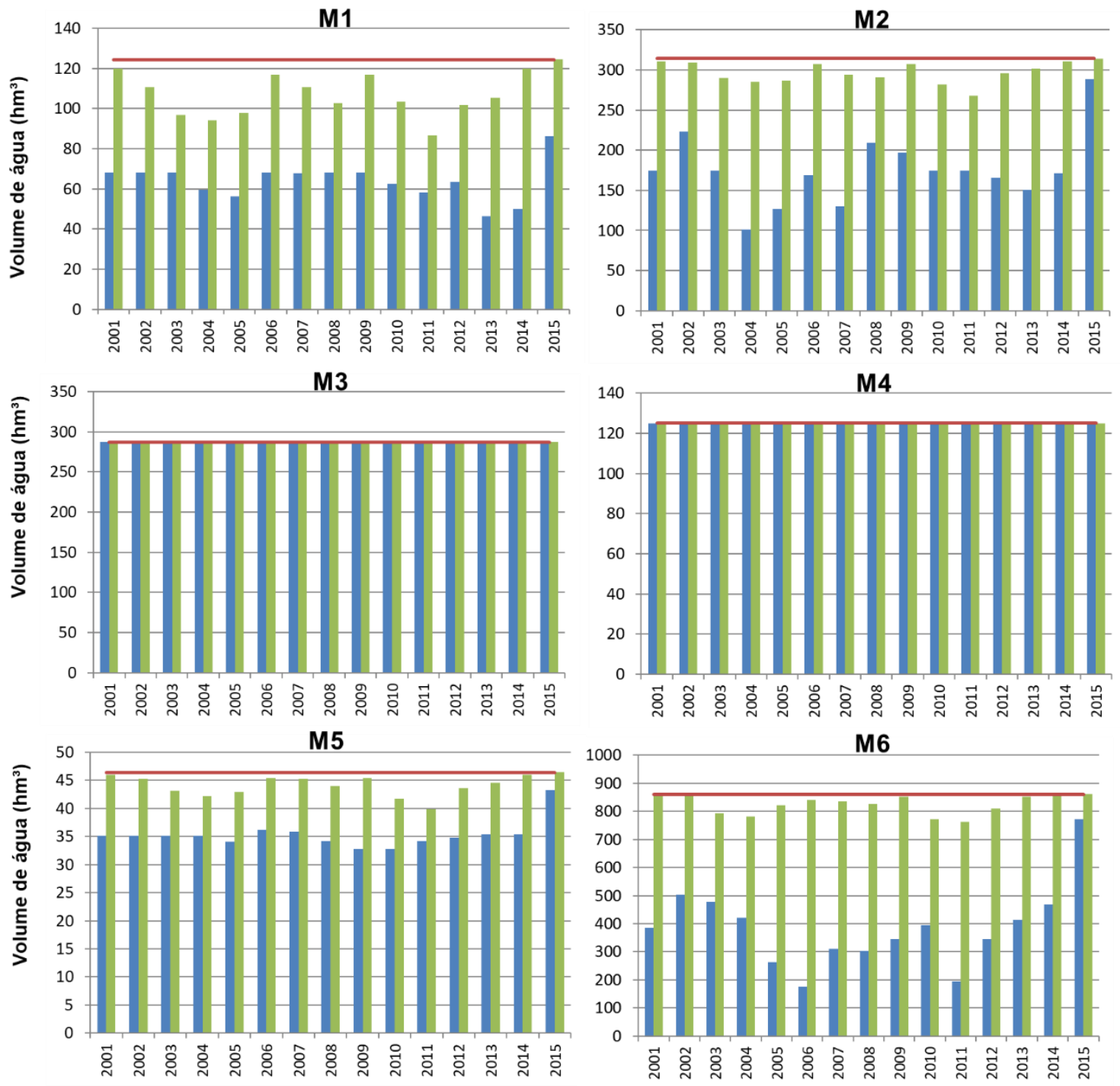

—Alocação (CB) —Demanda -Alocação (CB+GW) 
Figura 3 - Volume anual de água subterrânea utilizada para alocação em todas as regiões ao longo os 15 anos de simulação (hm³)
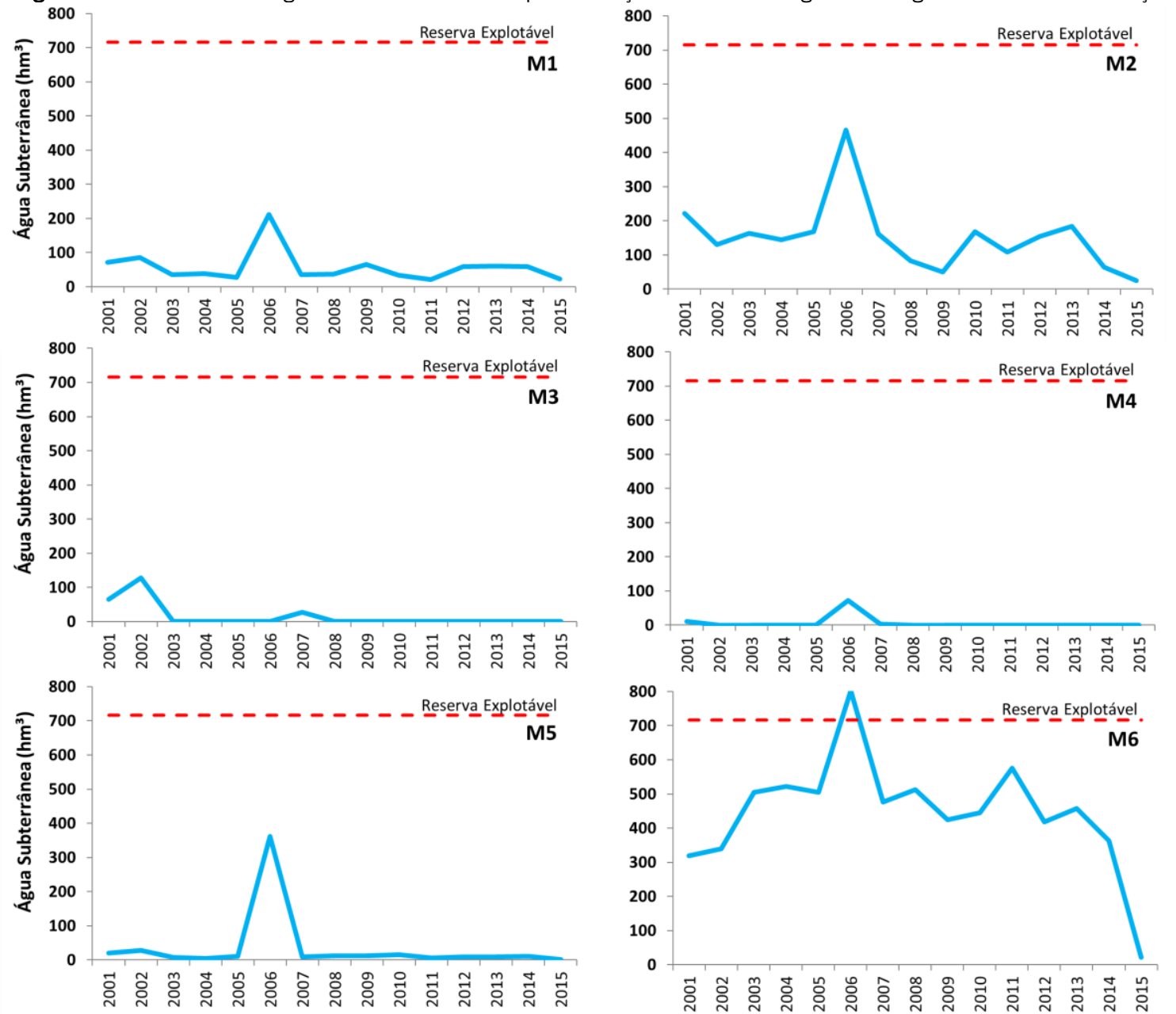

Nas Figuras 4 e 5 estão apresentadas as variações médias interanual e sazonal (mensal) do uso de mananciais superficiais e subterrâneos, para cada região estudada, em $\mathrm{hm}^{3}$. Nas regiões $M 1, M 2$ e M6 houve maior uso de água subterrânea ao longo dos anos, destacando-se o ano de 2006 (período de escassez). Nota-se que em alguns anos existe maior uso de água subterrânea, e em outros apenas a complementação com a água subterrânea mediante maior disponibilidade superficial.

A partir dessa análise anual podem ser vislumbradas algumas estratégias de uso conjunto: com a previsão de menor disponibilidade hídrica superficial poderia ser iniciado o uso de água subterrânea, principalmente nas regiões M1 e M2. Na região M5 percebemos que há contribuição subterrânea em praticamente todos os anos simulados, indicando possiblidade de adoção de práticas de uso conjunto com regras de operação revistas anualmente. Já na região M6 percebe-se um uso elevado de água subterrânea em diversos anos, evidenciando que esta região precisa de alternativas para enfren-

tar o recorrente cenário de escassez hídrica.

A dinâmica das variações mensais é apresentada na Figura 5; neste trabalho foi convencionado que as retiradas de água ocorrem entre agosto e dezembro, período que relaciona a maior disponibilidade hídrica superficial com o início da irrigação, durante 100 dias, conforme portaria do Departamento de Recursos Hídricos/RS (DRH/SEMA, 2017). Conforme a Figura 5 , a dinâmica do modelo hidroeconômico indica a retirada de água subterrânea em alguns meses do ano nos quais não há demanda agrícola entre os meses de março a outubro. Este resultado aponta uma estratégia operacional: a retirada de água subterrânea nos meses com pouca demanda permite o seu armazenamento nos reservatórios para uso nos meses em que existe demanda hídrica para irrigação. A retirada de todo este volume de água, que ocorre durante o ano, principalmente nas regiões M1, M2 e M6 não seria possível de ser concentrada somente nos meses de irrigação, pois poderia ocasionar superexplotação dos aquíferos. 
Figura 4 - Variação interanual do uso de água subterrânea e superficial em cada região (valor médio anual em hm³)

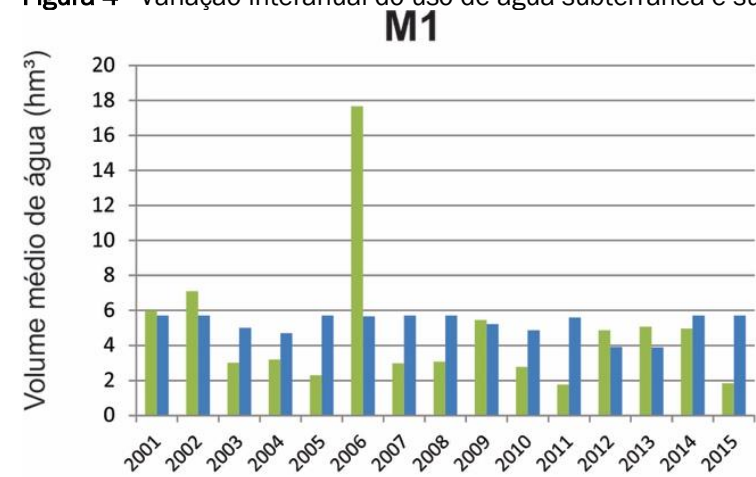
M2
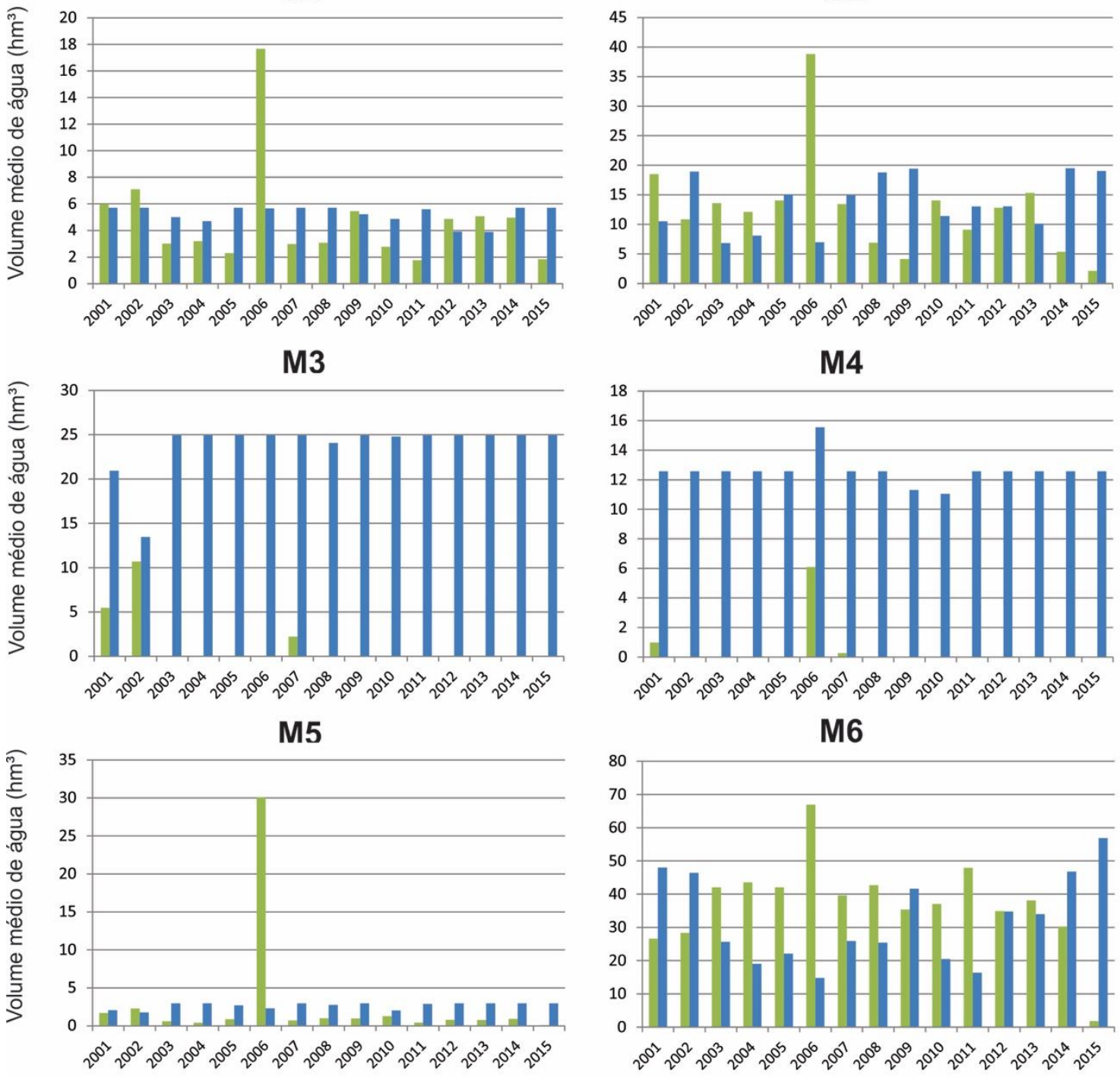

- Subterrânea

Superficial 
Figura 5 - Variação sazonal do uso de água subterrânea e superficial em cada região (valor médio mensal em hm³)

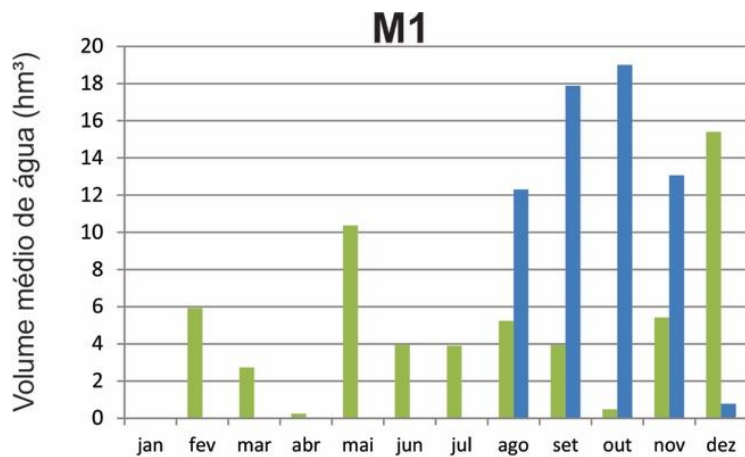

M3

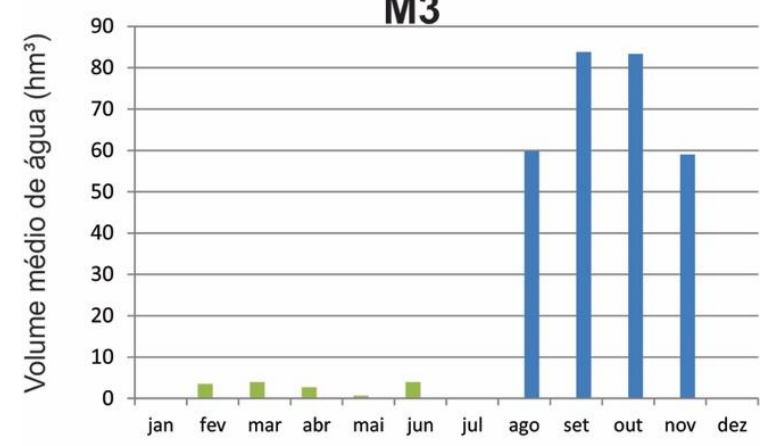

M5

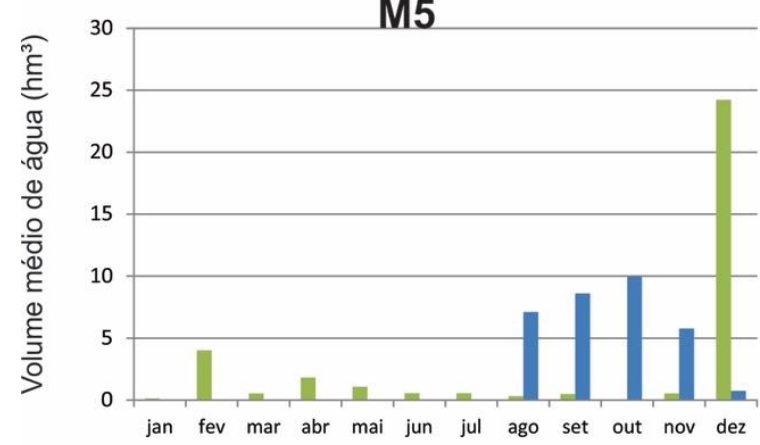

- Subterrânea

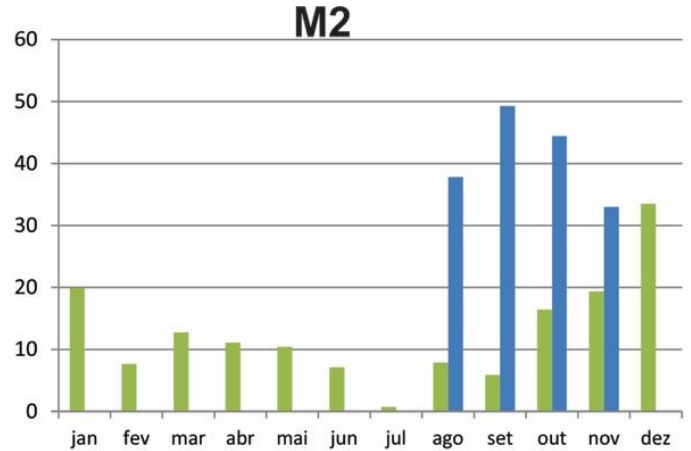

M4

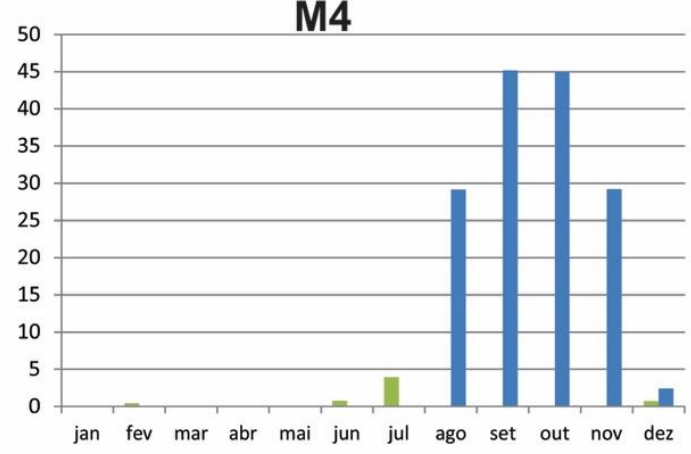

M6

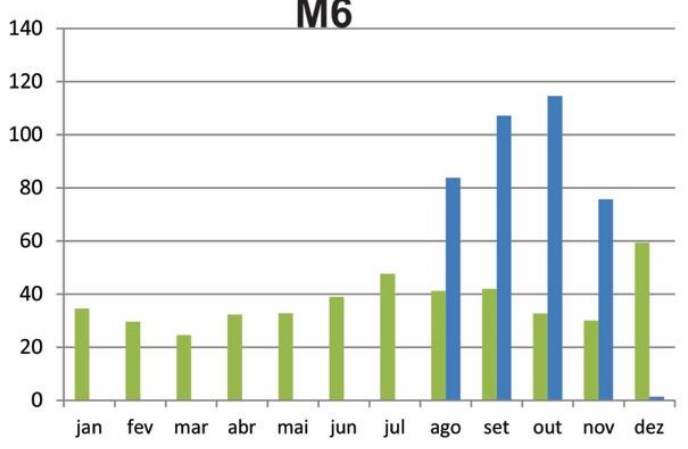

- Superficial
4.3. Impacto do uso de água subterrânea no custo da escassez

Na Figura 6 estão apresentados, acumulados para os 15 anos de simulação, a escassez hídrica $\left(10^{6} \mathrm{~m}^{3}\right.$ - linha) e o custo da escassez (milhões $\mathrm{R} \$$ - linha tracejada), respectivamente. Conforme esperado, o aumento da disponibilidade hídrica devido à alocação de água subterrânea causou redução na escassez hídrica. Nas regiões M6, M2 e M1 a redução foi de $93 \%, 88 \%$ e $72 \%$, respectivamente, representando um volume total de $6.604 \mathrm{hm}^{3}, 1.823 \mathrm{hm}^{3}$, e $649 \mathrm{hm}^{3}$ em 15 anos. Houve redução no custo da escassez em consequência ao acesso à maior quantidade de água e aumento no benefício econômico para os agricultores na BHSM: para as regiões M6, M2 e M1 a redução no custo da escassez foi respectivamente $96 \%$,
$93 \%$ e $81 \%$, representando um total de $\mathrm{R} \$ 1.469$ milhões, $\mathrm{R} \$$ 347 milhões, e R $\$ 92$ milhões em 15 anos. Nas demais regiões (M3, M4 e M5) os resultados das simulações apontaram escassez hídrica, porém em volume menor, já que estas regiões possuem demandas agrícolas mais próximas à disponibilidade hídrica superficial (Figura 2).

Conforme os resultados, na Região M6, que possui mais de $114 \mathrm{mil}$ ha de plantações de arroz e soja, o uso de $478 \mathrm{hm}^{3}$ adicionais de água subterrânea, em média, por ano, para complementar a demanda agrícola traria como benefício a redução no custo de escassez em R $\$ 98$ milhões anualmente. Na Região M2, que possui mais de 44 mil ha de área plantada, o uso de $162 \mathrm{hm}^{3} /$ ano adicionais de água subterrânea causaria uma redução no custo da escassez de $\mathrm{R} \$ 23$ milhões. 
Figura 6 - Escassez $\left(10^{6} \mathrm{~m}^{3}\right)$ e Custo da Escassez (milhões $\mathrm{R} \$$ ) acumulados para os 15 anos de simulação em cada região para o caso base e para o caso com água subterrânea

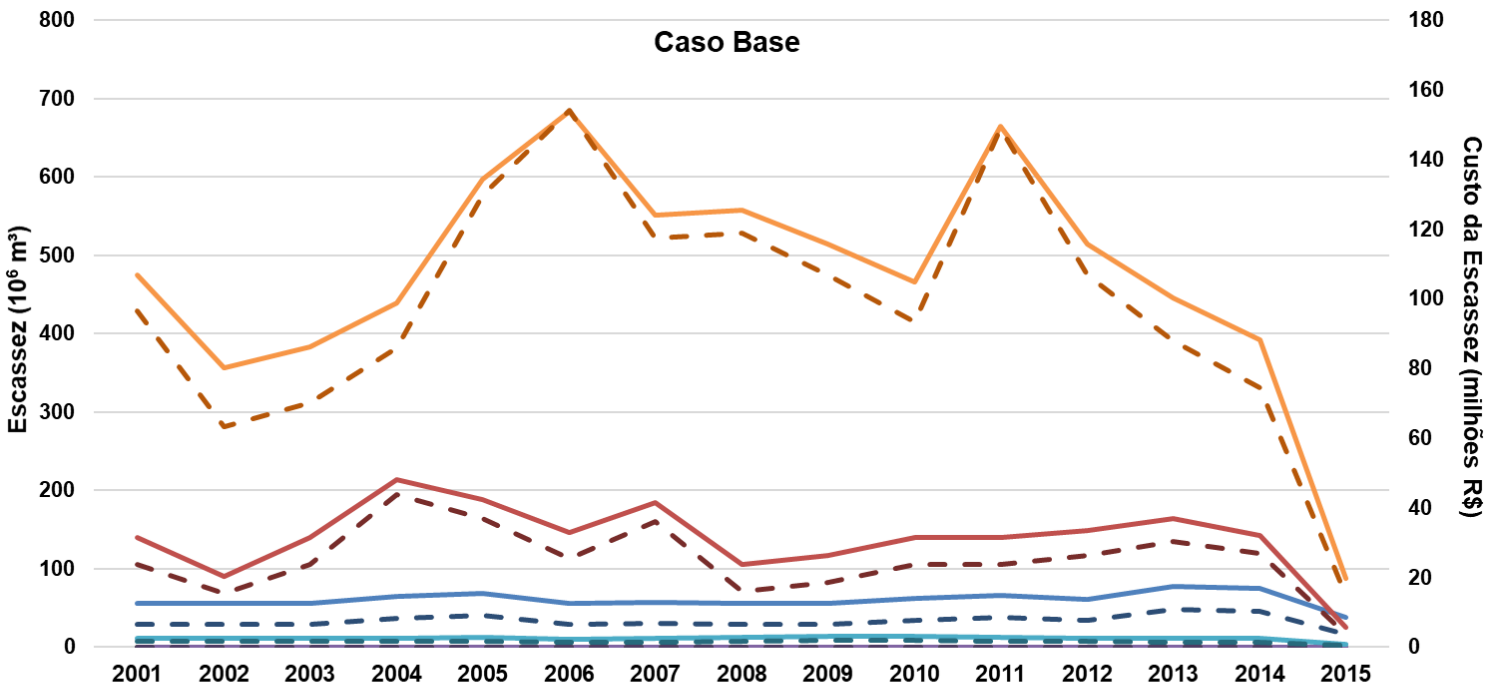

120

Caso Base + GW

12

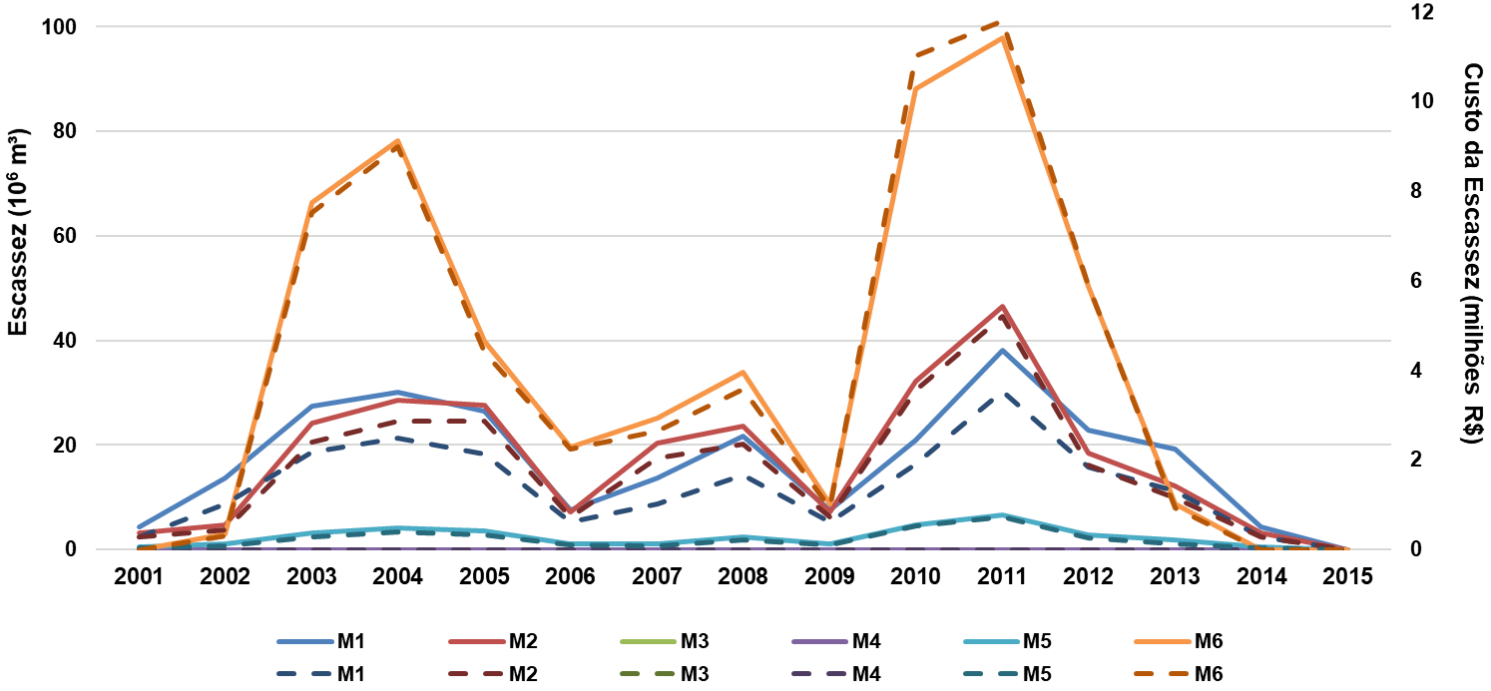

\subsection{Estratégias de uso conjunto para a BHSM}

Com base nestes resultados, podem ser configuradas algumas estratégias de uso conjunto aplicadas para a Bacia Hidrográfica do Rio Santa Maria:

i. Em meses de menor demanda hídrica, as atividades e práticas de manejo do solo devem privilegiar a potencialização da recarga;

ii. Implementação de um sistema de contabilidade hídrica para registrar "créditos hídricos" junto a cada produtor a partir de estimativas da quantidade de água recarregada em função das práticas de manejo adotadas (a associação com a recarga é um elemento incentivador para melhores práticas de uso e manejo do solo na bacia);

iii. Em meses de maior demanda hídrica (setembro a fevereiro) seriam utilizados mananciais subterrâneas para complementar ou substituir os mananciais superficiais (conforme a região), podendo ser configuradas duas possibilidades: (a) caso a bacia tenha implementada a cobrança pelo uso da água, os valores cobrados sobre o uso da água subterrânea sofreriam um abatimento em função da quantidade de créditos hídricos que cada usuário tenha contabilizado; (b) caso a bacia não tenha cobrança - ou ainda de forma complementar a cobrança - os volumes bombeados de água subterrânea seriam calculados em função da quantidade de créditos hídricos contabilizados.

Para detalhamento e implementação dessas estratégias, recomenda-se antes a realização de mapeamento hidrogeológico detalhado de cada região, mapeamento dos usos do solo e cobertura vegetal. Também são necessários estudos para quantificação da recarga hídrica em escala local; no entanto, sabe-se que, embora existam vários métodos, a quantificação da recarga aquífera é complexa, podendo haver imprecisões. Portanto, destaca-se a necessidade de estudos técnicos para permitir a identificação de áreas, técnicas e estratégias de uso conjunto que podem ser implementadas. 


\subsection{Reflexões para o gerenciamento dos recursos hídricos no Brasil}

Analisando o sistema de gerenciamento de recursos hídricos é possivel destacar oportunidades para o desenvolvimento de programas de uso conjunto embasados por instrumentos de gestão da Política Nacional de Recursos Hídricos, a Lei das Águas - 9.433/97 (BRASIL, 1997). Instrumentos de gestão podem ser aplicados para estimular o uso de mananciais superficiais ou subterrâneos conforme a sazonalidade e a distribuição, dentro de estratégias operacionais previamente determi- nadas, conforme destacado na Figura 7.

Em junho de 2018 foi aprovada pelo Conselho Nacional de Recursos Hídricos a Resolução n 202 que "estabelece diretrizes para a gestão integrada de recursos hídricos superficiais e subterrâneos que contemplem a articulação entre a União, os Estados e o Distrito Federal com vistas ao fortalecimento dessa gestão"; a aprovação de uma legislação específica sobre gestão integrada é um marco no sistema de gerenciamento dos recursos hídricos no Brasil. Na Figura 8 são destacados alguns tópicos da resolução.

Figura 7 - Instrumentos de gestão da PNRH e possíveis aplicações de uso conjunto

\section{Política Nacional de Recursos Hídricos (Lei das Águas 9.433/97) (BRASIL, 1997)}

\begin{tabular}{|c|c|}
\hline & Outorga \\
\hline 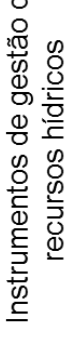 & $\begin{array}{l}\text { Assegura o controle } \\
\text { quantitativo e qualitativo } \\
\text { dos usos da água e o } \\
\text { efetivo exercício dos } \\
\text { direitos de acesso à } \\
\text { água, através da } \\
\text { preservação do uso } \\
\text { múltiplo. } \\
\text { (BRASIL, 1997) }\end{array}$ \\
\hline 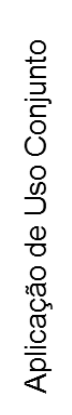 & $\begin{array}{l}\text { Definição de usos } \\
\text { prioritários; } \\
\text { Identificação de } \\
\text { alternativas de fonte de } \\
\text { água; } \\
\text { Destinação de água } \\
\text { para usos prioritários } \\
\text { pré-definidos em } \\
\text { épocas de escassez, } \\
\text { Planejamento frente à } \\
\text { situações de conflitos. }\end{array}$ \\
\hline
\end{tabular}

\begin{tabular}{|c|}
\hline Cobrança \\
\hline Reconhece a água \\
como bem econômico, \\
indica ao usuário o seu \\
real valor, incentiva o \\
uso racional, obtém \\
recursos financeiros \\
para o financiamento de \\
programas e \\
intervenções. \\
(BRASIL, 1997) \\
\hline
\end{tabular}

Incentivar usos economicamente mais rentáveis:

Incentivar uso de água de diferentes mananciais:

Subsidiar estudos de uso conjunto

Financiar obras de melhoria no sistema hídrico.

\begin{tabular}{|c|}
\hline Planos de Recursos Hídricos \\
\hline Fundamenta e orienta o \\
gerenciamento dos recursos hídricos \\
através do diagnóstico, análise de \\
alternativas e planejamento em longo \\
prazo das disponibilidades e \\
demandas futuras dos recursos \\
hídricos, previsão de conflitos e \\
priorização de usos. \\
(BRASIL, 1997) \\
Análise das demandas e \\
disponibilidades atuais e futuras; \\
Caracterização da interação rio- \\
aquífero; \\
Identificação de conflitos pelo uso de \\
água e soluções; \\
Identificação de estruturas existentes \\
(canais, reservatórios, poços) e \\
possibilidades de integração, \\
Desenvolvimento de mecanismos de \\
planejamento que otimizem o uso \\
dos recursos hídricos.
\end{tabular}

Figura 8 - Tópicos da Resolução n ${ }^{\circ} 202$ do CNRH de 28 de junho de 2018

\section{Resolução do CNRH de 28 de junho de 2018 (MMA, 2018)}

Definição (Art $2^{\circ}, \mathrm{VIII}$ ): Gestão integrada de recursos hídricos superficiais e subterrâneos é um conjunto de procedimentos que visam a garantir a sustentabilidade hídrica quanto ao aproveitamento integrado das águas superficiais e subterrâneas

Aplicação (Art $3^{\circ}$ ): Aquíferos livres e rios perenes onde exista conectividade direta entre águas superficiais e subterrâneas.

A gestão integrada contemplará avaliações hidrológicas integradas e deverá observar, no mínimo, os seguintes itens (Art $4^{\circ}$ )

I - Delimitação das áreas de recarga e de contribuição dos aquíferos para os rios diretamente conectados;

II - Estimativa da contribuição dos aquíferos para a vazão de base dos rios;

III - Estimativa da recarga e as reservas explotáveis e renováveis, considerados os efeitos do uso e ocupação do solo;

IV - Estimativa da disponibilidade hídrica integrada subterrânea e superficial para os diversos usos, considerando os incisos anteriores;

$\mathrm{V}$ - As redes de monitoramento hidrometeorológica e hidrogeológica necessárias.

A gestão integrada deverá ser definida por bacia hidrográfica, ou trecho dela, considerando os aquíferos ou sistemas aquiferos existentes $\left(\S 5^{\circ}\right.$, Art $\left.6^{\circ}\right)$.

Os atos administrativos formalizados devem ser conjuntos quando envolverem mais de uma autoridade

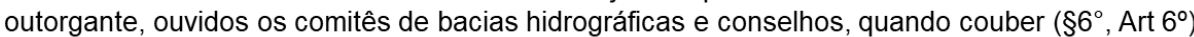




\section{CONCLUSÃO}

A aplicação de estratégias de uso conjunto de água superficial e subterrânea, mediante estudos técnicos e integração entre equipes gestoras, tomadores de decisão e usuários, pode contribuir para a efetividade da gestão das águas, evitar conflitos, e aumentar os benefícios econômicos. Conforme apresentado neste trabalho, existem amplas possibilidades previstas na legislação brasileira de recursos para a implementação destas estratégias.

Os resultados da aplicação do modelo hidroeconômico indicaram a ocorrência de eventos de escassez hídrica na Bacia $\mathrm{Hi}$ drográfica do Rio Santa Maria. A execução do modelo com disponibilidade de água subterrânea indicou não apenas um potencial de uso desse manancial para reduzir a escassez em todas as regiões, mas também indicativos de uma lógica operacional. Nas regiões M6, M2 e M1 houve uma redução na escassez hídrica de $93 \%, 88 \%$ e $72 \%$, respectivamente, representando um volume médio anual de $44010^{6} \mathrm{~m}^{3}, 12210^{6} \mathrm{~m}^{3}$, e $4310^{6} \mathrm{~m}^{3}$. De maneira semelhante, o uso de água subterrânea teve impactos favoráveis no custo da escassez: observouse que para as regiões M6, M2 e M1 houve redução respectivamente de $96 \%, 93 \%$ e $81 \%$, representando um total médio anual de $\mathrm{R} \$ 98$ milhões, $\mathrm{R} \$ 23$ milhões, e R\$ 6 milhões.

Com relação à operação do sistema e às estratégias de uso conjunto, percebe-se que é possivel otimizar o atendimento às demandas agrícolas na BHSM, explorando: (i) a retirada de água subterrânea durante períodos de menor demanda para armazenamento e utilização em épocas de irrigação (como em M1, M2 e M6); (ii) a complementação da disponibilidade superficial com retiradas subterrâneas ao longo dos anos (como em M1, M2, M5 e M6); (iii) o direcionamento de práticas de manejo do solo para privilegiar a recarga subterrânea; (iv) a utilização de instrumentos de gestão e sistemas de "créditos hídricos" para incentivar o manejo do solo visando a recarga aquífera, e (v) a utilização do instrumento da cobrança pelo uso da água para incentivar o uso de determinando manancial ao longo das épocas do ano e mediante variações nas demandas e disponibilidades.

No desenho das estratégias de uso conjunto deve-se observar os aspectos técnicos do meio físico, pois retiradas subterrâneas podem impactar em redução nos recursos superficiais e em perdas adicionas por evaporação (quando houver armazenamento em reservatórios superficiais). Destaca-se ainda que os resultados deste estudo são limites superiores para os benefícios econômicos, e necessitam de refinamento considerando-se unidades geográficas menores e simulações que considerem o comportamento real dos sistemas aquíferos nessas unidades, bem como a sua interação com a hidrologia superficial e subsuperficial. Entretanto, a utilidade destes resultados, e dos modelos de planejamento de larga escala como o modelo hidroeconômico aqui apresentado, reside justamente na capacidade de apontar direções e identificar insights acerca de alternativas operacionais na bacia e dos benefícios potenciais, de modo a mostrar onde e como o estudo pode ser refinado posteriormente.

\section{AGRADECIMENTOS}

Os autores agradecem ao Conselho Nacional de Desenvolvimento Científico e Tecnológico (CNPq) pelas bolsas de Mestrado e de Produtividade em Pesquisa. Os autores agradecem o apoio da CAPES, projeto 88881.064986/2014-01.

\section{REFERÊNCIAS}

ABDOLVANDI, A.F.; PARSAMEHR, A.; ABAZADEH, H.; ESLAMIAN, S.; HOSSEINIPOUR, Z. Conjunctive Use of Surface and Groundwater Resources Using System Dynamics Approach (Case Study: Namroud Dam). World Environmental and Water Resources Congress, p. 323-34, 2014.

AGÊNCIA NACIONAL DE ÁGUAS - ANA. Disponibilidade e Demandas dos Recursos Hídricos no Brasil. Caderno de Recursos Hídricos, Brasília/DF, 134p, 2005.

AGÊNCIA NACIONAL DE ÁGUAS - ANA. Caderno da Região Hidrográfica. Uruguai. Brasília/DP, 132 p., 2006.

AGÊNCIA NACIONAL DE ÁGUAS - ANA. Atlas Brasil: Abastecimento Urbano de Água: Panorama Nacional, v.1. Brasília, DF, 72 p. 2010.

AGÊNCIA NACIONAL DE ÁGUAS - ANA. Conjuntura dos Recursos Hídricos no Brasil. Brasília, DF, 432 p., 2013.

AGÊNCIA NACIONAL DE ÁGUAS - ANA. Hidroweb. Disponível em: http://www.snirh.gov.br/hidroweb/. Acesso em 2016.

BRASIL. Lei n 9.433. de 8 de janeiro de 1997. Institui a Política Nacional de Recursos Hídricos, cria o Sistema Nacional de Gerenciamento de Recursos Hídricos, Brasília, DF, 1997.

BROOKE, A., KENDRICK, D., MEERAUS, A., AND RAMAN, R. GAMS: A user's guide. GAMS Development Corporation, 1998.

CÂMARA DOS DEPUTADOS. Projeto de Lei que dispõe sobre a definição de serviços ambientais e dá outras providências. 2007.

COLLISCHONN, W., ALLASIA, D.G., SILVA, B.C., TUCCI, C.E.M. The MGB-IPH model for large-scale rainfall-runoff modeling. Hydrol. Sci. J. v. 52, 878 - 895, 2007.

COMPANHIA DE PESQUISA EM RECURSOS MINEIRAIS - CPRM. Mapa Geológico do Rio Grande do Sul, escala 1:750.000. Serviço Geológico Brasileiro, 2007.

COMPANHIA DE PESQUISA EM RECURSOS MINEIRAIS - CPRM. Atlas Pluviométrico do Brasil: Isoietas Anuais na escala 1:5.000.000. Disponivel em: http://www.cprm.gov.br/publique/Hidrologia/Mapas-e-Publicacoes/Atlas-Pluviometrico-doBrasil-1351.html. Acesso em 2019.

DAI, C.; CAI, Y.P.;. LU, W.T.; LIU, H.; GUO, H.C. Conjunctive Water Use Optimization for Watershed-Lake Water Distribution System under Uncertainty: A Case Study. Water Resources Management, v. 30, p. 4429-4449, 2016. 
DEPARTAMENTO DE RECURSOS HÍDRICOS DA SECRETARIA DO AMBIENTE E DESENVOLVIMENTO SUSTENTÁVEL DRH/SEMA. Plano de Recursos Hídricos da Bacia Hidrográfica do Rio Santa Maria, 2016.

DEPARTAMENTO DE RECURSOS HÍDRICOS DA SECRETARIA DO AMBIENTE E DESENVOLVIMENTO SUSTENTÁVEL DRH/SEMA. Portaria $n^{\circ} 443 / 2017$ que prorroga o prazo da outorga para captação ou derivação de água superficial, mediante cadastro, aos usuários localizados na bacia hidrográfica do Rio Santa Maria e modifica a tabela anexa à portaria do $D R H n^{\circ}$ 1206/2015. Porto Alegre, 2017.

DRAPER, A.J.; JENKINS, M.W.; KIRBY, K.W.; LUND, J.R.; HOWITT, R.E. Economic-Engineering Optimization for California Water Management. Journal of Water Resources Planning and Management, v. 129, p. 155-164, 2003.

ECKHARDT, K. How to construct recursive digital filters for base flow separation. HydrologicalProcess, v. 19, p. 507-515, 2005.

FAN, F. M; BUARQUE, D. C.; PONTES, P. R. M.; COLLISCHONN, W. Um mapa de respostas de unidades hidrológicas para a América do Sul. In: SIMPÓSIO BRASILEIRO DE RECURSOS HÍDRICOS, 23., 2015. Anais [...]. Brasília/DF, 2015.

FARR, T.G., CARO, E., CRIPPEN, R., DUREN, R., HENSLEY, S., KOBRICK, M., PALLER, M., RODRIGUEZ, E., ROSEN, P., ROTH, L., SEAL, D., SHAFFER, S., SHIMADA, J., UMLAND, J., WERNER, M., BURBANK, D., OSKIN, M., ALSDORF, D. The shuttle radartopography mission. Rev. Geophys, v. 45, n. 2, p. 241-262, 2007.

FASAKHODI, A., NOURI, S., AND AMINI, M. Water resources sustainability and optimal cropping pattern in farming systems: A multi-objective fractional goal programming approach. Water Resources Management, v. 24, p. 4639-4657, 2010.

FILIMONOVA, A.A; BALDENKOV, M.G. A Combined-Water-System Approach for Tackling Water Scarcity: Application to the Permilovo Groundwater Basin, Russia. Hydrogeology Journal, v. 24, p. 489-502, 2015.

GLEESON, T.; WADA, Y.; BIERKENS, M.F.; VAN BEEK, L.P. Water balance of global aquifers revealed by groundwater footprint. Nature, v. 488, p. 197-200, 2012.

GROUNDWATER GOVERNANCE GLOBAL FRAMEWORK FOR ACTION - GGGFA. Global Framework for Action. 2015, 118p.

HERRÁlZ, A.D. La Importancia de las Aguas Subterráneas. Revista Real Academia de Ciencias Exactas, Físicas y Naturales, v. 103, p. 97-114, 2009.

HOWITT, R. E.; MEDELLÍN-AZUARA, J.; MACEWAN, D.; LUND, J. R. Calibrating disaggregate economic models of agricultural production and water management. Environmental Modelling \& Software, v. 38, p. 244-258, 2012.

Instituto Brasileiro de Geografia e Estatística - IBGE. Banco de dados: Cidades. 2015
JENKINS, M.W.; LUND, J.R.; HOWITT, R.E.; DRAPER, A.J.; MSANGI, S.M.; TANAKA, S.K.; RIZTEMA, R.S.; MARQUES, G.F. Optimization of California's Water Supply System: Results and Insights. Journal of Water Resources Planning and Management, v. 130, p. 271-280, 2004

KAHIL, M.T.; WARD, F.A.; ALBIAC, J.; EGGLESTON, J.; SANZ, D. Hydro-Economic Modeling with Aquifer-River Interactions to Guide Sustainable Basin Management. Journal of Hydrology, v. 539, p. 510-529, 2016.

MANI, A.; TSAI, F.; KAO, S.; NAZ, B.; ASFAQ, M.; TASTOGI, D. Conjunctive Management of Surface and Groundwater Resources under Projected Future Climate Change Scenarios. Journal of Hydrology, v. 540, p. 397-411, 2016.

MARQUES, G.F.; LUND, J.R.; HOWITT, R.E. Modeling Conjunctive Use Operations and Farm Decisions with Two-Stage Stochastic Quadratic Programming. Journal of Water Resources Planning and Management, v. 136, p. 386-394, 2010.

MATTIUZI, C.D.P.; KIRCHHEIM, R.; COLLISCHONN, W.; FAN, F.M. Estimativa De Recarga Subterrânea A Partir Da Separação De Escoamento De Base Na Bacia Hidrográfica Do Rio Ibicuí (América Do Sul). Revista Águas Subterrâneas, v 29, p. 285-300, 2015.

MATTIUZI, C.D.P. Gestão Integrada dos Recursos Hídricos: alocação otimizada com uso conjunto de água superficial e subterrânea para redução da escassez hídrica na Bacia Do Rio Santa Maria/RS. Dissertação (Mestrado) - Instituto de Pesquisas Hidráulicas, Universidade Federal do Rio Grande do Sul, 93p, 2018.

MATTIUZI, C.D.P.; MARQUES, G.F.; MEDELLÍN-AZUARA, J. Reassessing Water Allocation Strategies and Conjunctive Use do Reduce Water Scarcity and Scarcity Costs for Irrigated Agricutlure in Southern Brazil. Water, v. 11, 24 p, 2019.

MINISTÉRIO DO MEIO AMBIENTE. Resolução $n^{\circ} 202$ de 28 de junho de 2018 do Conselho Nacional de Recursos Hídricos. 2018, 3p.

ORGANIZAÇÃO DAS NAÇÕES UNIDAS - ONU. The Millennium Development Goals Report, 2015, 75p.

PULIDO-VELAZQUEZ, M.; MARQUES, G.F.; JENKINS, M.W.; LUND, J.R. Conjunctive use of ground and surface water: Classical approaches and California examples. Proc. In: WORLD WATER CONGRESS, 11., 2003. Proceedings [...]. International Water Resources Association, Madrid, Spain, 2003.

RAUL, S.K.; PANDA, S.N. Simulation-Optimization Modeling for Conjunctive Use Management under Hydrological Uncertainty. Water Resources Management, v. 27, p. 1323-1350, 2013.

REZAEI, F.; SAFAVI, H.R.; ZEKRI, M. A Hybrid Fuzzy-Based MultiObjective PSO Algorithm for Conjunctive Water Use and Optimal Multi-Crop Pattern Planning. Water Resources Management, v. 31, p. 1139-1155, 2017. 
ROSS, A. Speeding the Transition towards Integrated Groundwater and Surface Water Management in Australia. Journal of Hydrology, 2017.

SAHUQUILLO, A. La Importancia de las Aguas Subterráneas. Rev.R.Acad.Cienc.Exact.Fís.Nat. (Esp), v. 103, p. 97-114, 2009.

SINGH, A. Simulation and Optimization Modeling for the Management of Groundwater Resources. II: Combined Applications. Journal of Irrigation and Drainage Engineering, v. 140, p. 1-9, 2014.

SINGH, A. Optimal Allocation of Resources for Increasing Farm Revenue under Hydrological Uncertainty. Water Resources Management, v. 30, p. 2569-2580, 2016.
SOARES, L.C.; VELÁSQUEZ, L.N.M. Estimativa da Recarga Aquífera na Bacia do Rio Riachão, Norte de Minas Gerais. Águas Subterrâneas, v. 27, p. 104-120, 2013.

TABARI, M.M.R.; YAZDI, A. Conjunctive use of surface and groundwater with inter-basin transfer approach: case study $\mathrm{Pi}-$ ranshahr. Water Resour Manag, v. 28, p.1887-1906, 2014.

WU, X.; ZHENG, Y.; WU, B.; TIAN, Y.; HAN, F.; ZHENG, C. Optimizing Conjunctive Use of Surface Water and Groundwater for Irrigation to Address Human-Nature Water Conflicts: A Surrogate Modeling Approach. Agricultural Water Management, v. 163, p. 380-392, 2015. 